\title{
A RARE MALIGNANCY OF SINONASAL TRACT- TRANSITIONAL CELL CARCINOMA: A CASE REPORT
}

Prakash S.B ${ }^{1}$, Nishan ${ }^{2}$

\section{HOW TO CITE THIS ARTICLE:}

Prakash SB, Nishan. "A rare malignancy of sinonasal tract- transitional cell carcinoma: a case report". Journal of Evolution of Medical and Dental Sciences 2013; Vol2, Issue 36, September 9; Page: 6946-6950.

ABSTRACT: A 30-year old female presented with a 8-month history of left nasal obstruction associated with recurrent episodes of epistaxis. Left nasal cavity was filled with polypoidal mass. Computed tomography revealed a mass present in the left nasal cavity, appears to be arising from ethmoidal air cells and lateral nasal wall. Diagnostic Nasal Endoscopy was done and biopsy was taken. Report came as sinonasal malignancy of transitional cell type. Endoscopy assisted, surgical excision of the mass was done and later she was referred higher centre for further management. Non-keratinizing carcinoma (Transitional type) of the sinonasal tract is a rare entity and there are only few reports concerning this type of malignancy. This may be partly because of its diagnostic difficulty due to many synonyms such as Schneiderian carcinoma, cylindrical cell carcinoma and transitional cell carcinoma.

KEYWORDS: Non-keratinizing carcinoma, Schneiderian carcinoma, Transitional cell carcinoma, Cylindrical cell carcinoma, Ringertz carcinoma, Respiratory epithelial carcinoma.

CASE REPORT: A 30 year old female, housewife from Mysore district presented to our OPD with a 8months history of progressively worsening left nasal obstruction associated with episodes of epistaxis. There were no other symptoms in this previously well lady.

Clinical examination showed a pinkish, polypoidal mass filling entire left nasal cavity, can be probed all around except on its lateral aspect, insensitive and bleeds on touch. Nasal septum was deviated to the opposite side.
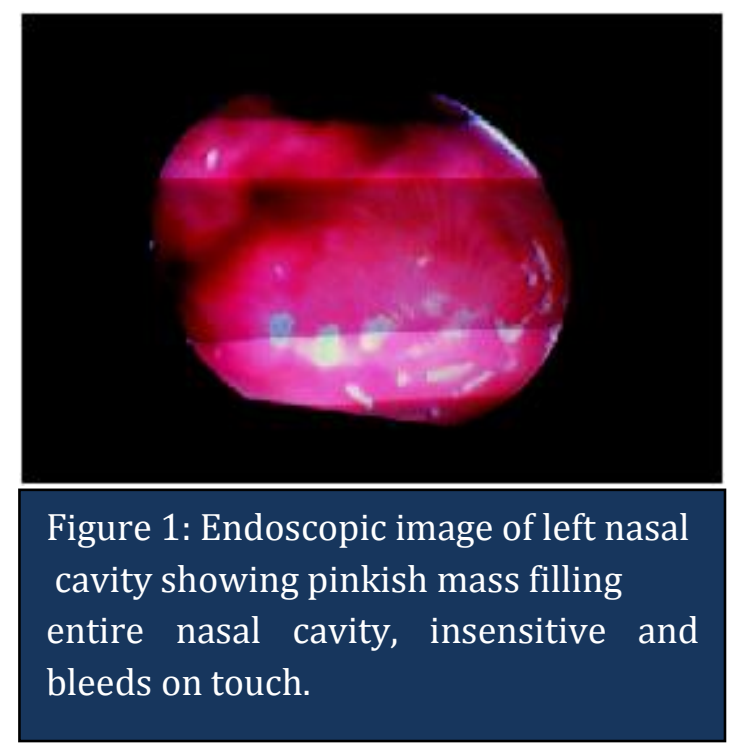

Posterior rhinoscopy showed mass filling the left choana. A complete head and neck examination did not reveal any evidence of cervical lymphadenopathy. 
A computed tomography scan of the paranasal sinuses showed homogeneously-enhancing mass in the left nasal cavity, ethmoidal region, left choana and pushing the nasal septum to the right side. The mass appeared to be arising from the left anterior ethmoidal air cells and from lateral wall. There was also thinning and displacement of the ipsilateral lamina papyracea noted but no evidence of any bony erosion. Cribriform plate was not eroded.

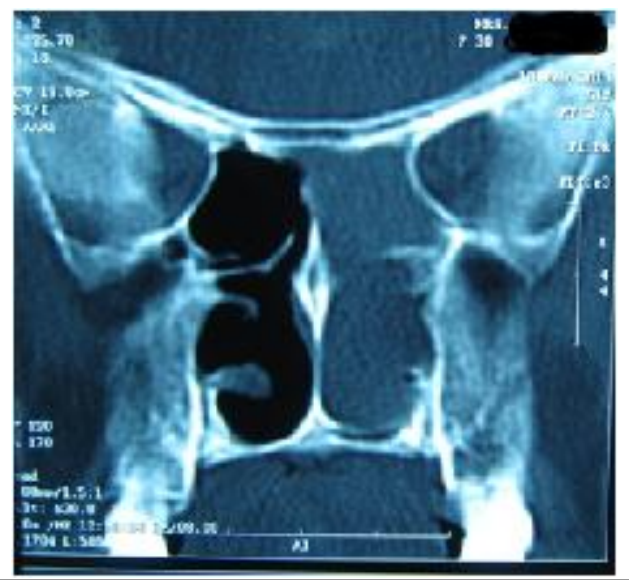

Figure 2: Contrast computed tomography scan, coronal section. A homogeneously enhancing mass is seen in the left nasal cavity. The Mass appears to be arising from the left anterior ethmoidal air cells, lateral wall. No evidence of subperiosteal or extraconal extension is seen within the left orbit.

After getting all necessary investigations, we decided to take biopsy. Histopathological examination revealed a non-keratinizing (transitional cell) carcinoma. Conset was taken. The available surgical modalities are Medial maxillectomy via lateral rhinotomy, Intranasal ethmoidectomy, Ethmoidectomy through Caldwell luc approach and Endoscopic assisted removal of the tumor. We planned for Endoscopic assisted tumor removal. First we removed the mass from the nasal cavity then we removed the mass near maxillary sinus ostium and lateral wall. Later complete removal of the mass from the ethmoids was done. Both lamina papyracea and cribriform plate was intact. During the surgery we had difficulty in identifying the normal anatomy of lateral nasal wall. There was bleeding but complete hemostasis was achieved using cautery. Post operative blood transfusion done. The patient recovered well later. Higher intravenous antibiotics were given for one week. Later patient was referred to higher center for radiotherapy.

She is under good follow-up and she is showing improvement.

DISCUSSION: Malignant sinonasal tumours represent less than $1 \%$ of all cancers seen in humans and about $3 \%$ of all malignancies of the head and neck region ${ }^{1}$. Of this $15-20 \%$ are transitional cell carcinomas $^{2-4}$. Despite the low rate of malignancy arising in the sinonasal tract, a great variety of histological types of tumours may be found. The use of electron microscopy and more recent advances in immunohistochemistry and molecular biology have made it possible to refine the criteria for their correct recognition 
Transitional cell carcinoma, also known as non-keratinizing squamous cell carcinoma, cylindrical cell carcinoma or Schneiderian carcinoma, is a rare tumour composed of malignant proliferating cells derived from sinonasal respiratory (schneiderian) epithelium. The name cylindrical cell carcinoma was first coined by Ringertz in $1938^{5}$ and recommended as the preferred term by Shanmugaratnam in the WHO classification of $1991^{6}$.

Grossly, the tumours grow in most cases as exophytic masses showing either a corrugated or a smooth surface. They may arise from the Maxillary antrum, the lateral nasal wall or the ethmoid, the maxillary antrum being the most frequent site ${ }^{7,8}$.Microscopically, Transitional cell carcinoma is composed of papillary fronds thick ribbons and poly stratified masses of cells that give rise quite often to invaginations of the surface epithelium, which at low magnification may mimic inverted papilloma.

The tumour cells are commonly cylindrical and have a tendency to form palisade arrangements perpendicular to the underlying basement membrane. The nuclei are atypical and show increased mitotic activity, as well as abnormal mitotic figures. The pattern of invasion is usually expansive, being characterised by pushing margins with focal infiltration of the stroma. The basement membrane remains in most cases conspicuous, despite stromal infiltration, which should not be regarded as carcinoma in situ. Foci of squamous metaplasia, with transition from cylindrical to squamous epithelium, are not uncommon and when extensive these tumours may be indistinguishable from squamous cell carcinoma. This resulted in denominations such as "transitional cell carcinoma" and non-keratinizing squamous cell carcinoma", which may be confusing, the first because the term transitional has also been applied to carcinomas of the lymphoepithelial type, and the second due to the fact that tumours called "non-keratinizing squamous cell carcinoma" also have foci of keratinisation ${ }^{9}$.

In addition, the term cylindrical cell carcinoma should be preferred to non-keratinizing squamous cell carcinoma because "pure" cylindrical cell carcinomas, without any squamous cell component, carry a better prognosis than conventional squamous cell carcinomas ${ }^{10}$. Very recent observations suggest a strong etiologic relationship of transitional cell carcinoma to high-risk human papillomavirus ${ }^{11}$. A high proportion of these tumours show marked immunoreactivity for p16.

In our patient, histopathological examination showed Finger-like or papillary projections with fibrovascular core and multiple cell layers. Tumor cells showing loss of polarity, nuclear pleomorphism \& hyperchromasia.

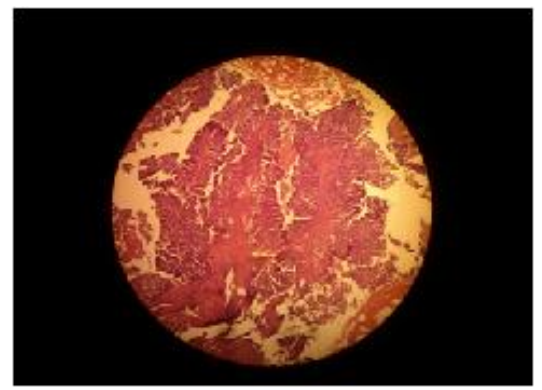

Figure 3: H\&E, 4X- Finger-like or papillary projections with fibrovascular core and multiple cell layers. 


\section{CASE REPORT}

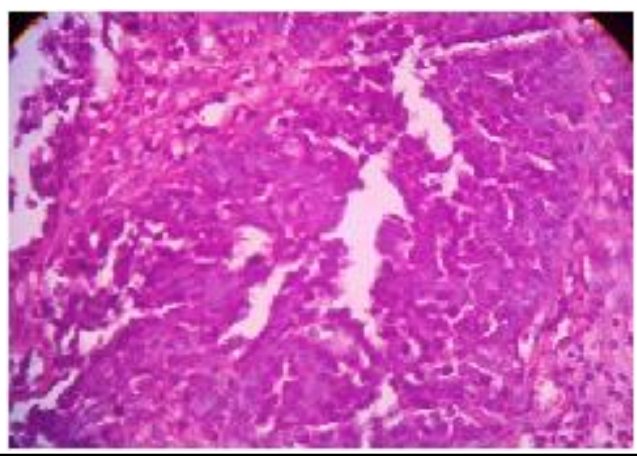

\section{Figure 4: H\&E 100X- Tumor cells showing loss of \\ polarity, nuclear pleomorphism \& hyperchromasia.}

More aggressive types of carcinoma, such as sinonasal undifferentiated carcinoma (SNUC) or high-grade adenocarcinoma may appear occasionally intermingled with Transitional cell carcinoma $^{3}$. Two cases of Transitional cell carcinoma with endodermal sinus-like features have been reported 12

A full examination of the resected specimen is therefore mandatory before labeling a tumour as a non keratinizing tumour. When schneiderian papillomas coexist with transitional cell carcinomas, or with other types of carcinoma, the two components usually appear demarcated from one another although in contiguity.

When the invaginating crypts of an inverted papilloma are filled with the cords and ribbons of a keratinizing or non-keratinizing squamous cell carcinoma, the lesion represents a conventional squamous cell carcinoma arising in an inverted papilloma, which implies a worse prognosis than that of transitional cell carcinoma.

\section{REFERENCES:}

1. Majumdar B, Kent S (1983). Malignant neoplasms of the nose and paranasal sinuses. A survey of cases treated in a regional centre. Clin Otolaryngol 8:97-102

2. Osborn DA. Nature and behavior of transitional tumors of the upper respiratory tract. Cancer 1970; 25:50-60.

3. Robin PE, Powell DJ, Stansbie JM. Carcinoma of the nasal cavity and paranasal sinuses: incidence and presentation of different histologic types. Clin Otolaryngol 1979; 4: 431-456.

4. El-Mofty SK, Lu DW. Prevalence of high-risk human papillomavirus DNA in non-keratinizing (cylindrical cell) carcinoma of the sinonasal tract. A distinct clinicopathologic and molecular disease entity. Am J Surg Pathol 2005; 29: 1367-1372.

5. Ringertz N (1938) Pathology of malignant tumours arising in the nasal and paranasal cavities and maxilla. Acta Otolaryngol Suppl 27:31-42

6. Shanmugaratnam K (1991) WHO histological typing of tumours of the upper respiratory tract and ear. Springer, Berlin Heidelberg New York.

7. Osborn DA (1956) Transitional cell growths of the upper respiratory tract. J Laryngol Otol 70:574-587.

8. Osborn DA (1970) Nature and behavior of transitional tumors in the upper respiratory tract. Cancer 25:50-60 
9. World Health Organization Classification of Tumours (2005) Pathology and genetics of tumours of the head and neck. IARC, Lyon

10. Friedmann I, Osborn DA (1982) Carcinoma of the surface epithelium (including ameloblastoma). In: Friedmann I, Osborn D (eds) Pathology of granulomas and neoplasms of the nose and paranasal sinuses. Churchill Livingstone, Edinburgh, pp 118-132

11. El-Moft y SK, Lu DW (2005) Prevalence of high-risk human papillomavirus DNA in nonkeratinising (transitional cell) carcinoma of the sinonasal tract. A distinct clinicopathologic and molecular disease entity. Am J Surg Pathol 29:1367-1372

12. Manivel C, Wick MR, Dehner LP (1986) Transitional (cylindric) cell carcinoma with endodermal sinus tumor-like features of the nasopharynx and paranasal sinuses. Clinicopathologic and immunohistochemical study of two cases. Arch Pathol Lab Med 110:198-202.

\section{AUTHORS:}

1. Prakash S.B.

2. Nishan

\section{PARTICULARS OF CONTRIBUTORS:}

1. Assistant Professor, Department of ENT, K. R. Hospital, MMCRI, Mysore.

2. Post Graduate, Department of ENT, K. R. Hospital, MMCRI, Mysore.

\section{NAME ADDRESS EMAIL ID OF THE} CORRESPONDING AUTHOR:

Dr. Prakash S.B., Door No. 136,

Vijayanagara $4^{\text {th }}$ Stage, $3^{\text {rd }}$ Phase, Mysore - 570018.

Email-prakashsb.mmc@gmail.com

Date of Submission: 20/08/2013.

Date of Peer Review: 21/08/2013.

Date of Acceptance: 02/09/2013.

Date of Publishing: 04/09/2013 